\section{Pitfalls of adapting emergency contraception CEU guidance}

The introduction of a new oral emergency contraceptive (EC), ulipristal acetate (UPA) with a higher up-front cost, has led many clinicians to consider trying to identify women at higher risk of pregnancy so that they can be preferentially offered the drug that works closer to ovulation. These attempts, however well meaning, are flawed, are not based on the published evidence, go against best practice guidance as established by the Clinical Effectiveness Unit (CEU), and may deprive women at definite risk of pregnancy from making an informed choice.

If it were possible to determine, consistently and reasonably accurately, where a woman is in relation to ovulation we could reassure the majority of women that they did not need any EC. We know levonorgestrel (LNG) has no effect once the luteinising hormone (LH) surge has started and that UPA has not been shown to have any effect after the LH peak. ${ }^{1}$ However, ask any group of women and many will admit conceiving at times of the cycle when they would not expect to. There is good published evidence to support this clinical impression. More than half $(51 \%)$ of women with $\mathrm{LH}$ levels $>20 \mathrm{IU} / 1$ were not within 1 day either side of the predicted ovulation dates. $^{2}$ Of 32 women estimated to be in the luteal phase, because they knew the date of their last period and had regular cycles, 14 of them had not yet ovulated. ${ }^{3}$ All this confirms that estimates of risk based on last menstrual period and cycle length are very poor.

We also know that both LNG and UPA can delay ovulation so any calculations about date of ovulation after either has been used within a cycle become totally invalid and use of methods for any subsequent exposure can only be guided by the intercourse-treatment interval.

CEU guidance on emergency contraception ${ }^{4}$ clearly states that: "Health professionals should discuss individual need for emergency contraception and inform women about the different methods with regard to efficacy, adverse effects, interactions, medical eligibility and need for additional contraceptive precautions" and that "All eligible women presenting between 0 and 120 hours of UPSI [unprotected sexual intercourse] or within 5 days of expected ovulation should be offered a Cu-IUD [copper-containing intrauterine device] because of the low documented failure rate".

A recent publication ${ }^{5}$ tried to address what this means in different clinical situations.

In trying to be pragmatic and draw up flow diagrams clinicians go against advice from published guidance at their peril, be that because they apply more limitations (using UPA only at apparent 'mid-cycle') or go beyond the advice (repeating UPA more than once in a cycle/doubling up the UPA dose with liver enzyme inducers).

During a consultation we need to discuss all necessary issues to enable the woman to make a truly informed decision. Only she can decide how she perceives her risk and what course of action she wishes to take. Using the "What would you say if you were talking to your sister or your daughter?' criterion is a useful clinical principle. If the answer is different then we would argue that it is not good enough for anyone.

Financial hardship is not an excuse for lowering clinical standards. If commissioners oblige clinicians to go against clinical guidance then let them carry the responsibility for it. As clinicians we should teach and practise based on the best evidence published to date and only use 'expert' or consensus opinion where there is no evidence.

Only the woman can decide how at risk she 'feels' and how much she wishes to avoid pregnancy. If clinicians limit the information they give they need to take responsibility for the ensuing unplanned pregnancies.

\section{Anne Webb, FFSRH}

Consultant in Sexual and Reproductive Health, Liverpool Community Health, Liverpool, UK; anne.webb@liverpoolch.nhs.uk

\section{Pauline McGough, MRCOG, MFSRH}

Consultant in Sexual and Reproductive Health, Clinical Director, Sandyford, Glasgow, UK; paulinemcgough@nhs.net

\section{Louise Melvin, MRCOG, MFSRH}

Director, FSRH Clinical Effectiveness Unit, Sandyford, Glasgow, UK; louise.melvin@nhs.net

\section{Competing interests None.}

J Fam Plan Reprod Health Care 2012;38:270. doi:10.1136/jprhc-2012-100412

\section{References}

1 Brache V, Cochon L, Jesam C, et al. Immediate pre-ovulatory administration of $30 \mathrm{mg}$ ulipristal acetate significantly delays follicular rupture. Hum Reprod 2010;25: 2256-2263.

2 Espinós JJ, Rodriguez-Espinosa J, Senosiain $\mathrm{R}$, et al. The role of matching menstrual data with hormonal measurements in evaluating effectiveness of post coital contraception. Contraception 1999;60:243-247.

3 Stirling A, Glasier A. Estimating the efficacy of emergency contraception - how good are the data? Contraception 2002;66:19-22.

4 Faculty of Sexual and Reproductive Healthcare. Emergency Contraception. 2011. http://www.fsrh.org/pdfs/ CEUguidanceEmergencyContraception 11 . pdf [accessed 8 June 2012].

5 Prabakar I, Webb A. Emergency contraception. Br Med J 2012;344:61-64. 